\title{
Participation in Fadama User Groups (FUGs) as a medium of Social Capital and Empowerment in Kankara Local Community, Katsina State-Nigeria
}

\author{
${ }^{1,2}$ AminuRilwanu , ${ }^{1}$ Ma'rof Redzuan, ${ }^{1}$ Asnarulkhadi Abu-Samah

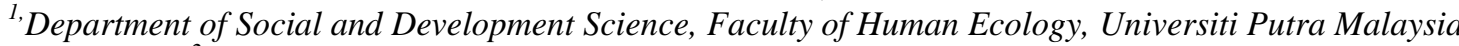 \\ ${ }^{2}$ Isa Kaita College of Education, PMB 5007, Dutsinma Katsina State, Nigeria.
}

\begin{abstract}
This paper was written to entails the results collected after conducting an empirical research which focus on Participation in Fadama User Groups (FUGs) as a medium of social capital and empowerment in Kankara local community, Katsina state Nigeria. This research was conducted because of the problems observed in the local community of low social capital and empowerment among the Fadama members'. The aim and objective here is to explore the level and relationships in participation, social capital and empowerment among the Fadama members'. The research work also try to explore how participation and social capital can transgress to empowerment. The total of 285 respondents was selected through random sampling techniques. And the instrument use for data collection was questionnaire. The collected data was analyzed by using Pearson correlation analysis to examine the strength of the relation between Fadama members' participation, social capital and empowerment among the respondents. The regression analysis was also run to examine how participation and social capital transgress to empowerment. The totals of 1176 members were engaged in the Fadama activities. And the research work use 285 sample size for effective coverage and collecting the un-bias and validated data which can justify the accrued result against the participating members'. The researcher arrived at the sample size through Kreijcie and Morgan (1977) sample size table. The data collected from the field was analyzed and the result shows that there is high level of participation, social capital and empowerment among the respondents. This result was comes up by using descriptive analysis. While the correlation analysis shown that there is significant positive medium relationship between participation and social capital ( $r=.343, p$ $=.000$ ). And the result shows that there is significant positive medium relationship between participation and empowerment among the respondent $(r=.346, p=.000)$. Meanwhile, the result shows that there is significant positive medium relationship between social capital and empowerment among the respondent $(r=.396, p$ $=.000)$. While the regression result indicated that the $\left(R^{2}=.207\right.$, adjusted $\left.R^{2}=.201\right)$ betweenparticipation in Fadama User Group (FUGs), social capital and empowerment.
\end{abstract}

Key words: Fadama User Groups (FUGs), Participation, Social capital and Empowerment.

\section{Introduction}

Fadama User Groups (FUGs) is a self-help organization set-up by peoples in the local community (Kankara) in order to boost the level of social capital and empowerment. It is a giant project designed and organized by the community themselves. These activities comprised a lot of things like; the use of Fadama resource areas for sustainable development. The resources underutilization includes: water quality protection and utilization, fisheries, pastoralist and cattle rearing, poultries production and land cultivation. While people participation or community participation according to Cohen and Uphoff(1977), sees it's as a process of people's involvement in the process of decision-making, planning process, implementation and evaluation process to share some benefits for community development and members' empowerment. And the real meaning of people's participation is the collective effort of the individual concerned to pool their efforts and whatever, in order to achieve maximum satisfaction, self-reliance and self-control (Cohen and Uphoff, 1977).

Therefore, Social capital is the ability or skills once gain/acquired to interact with other people in or outside their domain intellectually (Bourdieu, 1983; Bullen, Paul and Jenny Onyax, 2000).The amount of social capital one acquired may help him/her to attain certain level of empowerment in the participation arena. In Fadama User Groups (FUGs) efforts is being made to develop and empower their members with new ideas, skills and techniques for handling the Fadama activities. Examples, like the use of pesticide, herbicide, tractors operating machine and repairing workshops, building connection in and outside the community is part of the project capacity building. Similarly, building rapport with government and non-governmental organizations can help an individual members to acquire more social capital/benefits (Plateau and Moore, 1994;).

Meanwhile, Fadama User Groups (FUGs) activities in Kankara local community, is trying hard to enshrine trust among the members like network (structural) diversity, network size, demographic diversity and 
centrality of the network among the participating members(Bourdieu, 1983; Bullen, Paul and Jenny Onyax,2000).Cross and Cummings, (2004); White, (2002, p.260), opined that, through establishing good relationships among the FUGs members; the local community can purposefully employ and generate intangible and tangible benefits in a short or long terms. The benefits could be psychological,social, political or economic benefits among the participating members in the local community, from the Fadama activities. In due course people are getting involved more and more for the purpose of achieving some degrees of empowerment. Meanwhile, government and non-governmental organization are in assistant of their activities.

Moreover, such types of activities organized by Fadama User Groups (FUGs) are what led to the creation of social capital and empowerment through participation. Therefore, empowermentis the ability of someone to gain control socially, politically, economically as well as psychologically through access to information, knowledge and skills acquisition by the members' of Fadama User Groups (FUGs) through active engagement.More so, in the process of decision making; planning process, implementation and evaluation strategic process, Fadama members were also becoming involved for the purpose of getting the skills, experience and human capital. The individual self-efficacy, self-control as well as self-evaluation; should be adopted among the participating members'ofFadama User Groups (FUGs), so much so that members can perceive control (Laverack, 2006).

Similarly, Alison Harvey, (2010) added that participation process should include trust and understanding, access and information, voice and values, negotiation and mediation, resources (time and technical) as well as the ' $3 \mathrm{Cs}$ '- of participation (co-operation, co-ordination and collaboration) for successful members' empowerment.To operationalize the above concept in line to this research work, the researcher use Participation in Fadama User Groups (FUGs) as a medium for achieving social capital and empowermentin Kankara local community. Interestingly the above mention ideas highlighted by (Cohen and Uphoff, 1977; Laverack, 2006; as well as Alison, 2010) was accepted and adopted by the Fadama members to come up andcreate strong and reliable, trustworthy people's participation in Fadama User Groups (FUGs) for members' empowerment.

In addition to that social capital was created as a result of Participation in Fadama User Groups (FUGs) activities. The participating members' were agreed to come and join together and work as a family to achieve their target objectives (empowerment). Meanwhile, participation as a medium creates social capital and empowermentthrough trust, networking and confidentiality among the respondents. Rubert D. Putnam (2000) refers social capital as the collective value of 'social networks and the inclinations that arise from these networks to do things for one another. Putnam believes that, social capital can be measured by the amount of "trust" and "reciprocity" one get among the community members or individuals. While Newton (1997), considered social capital as subjective phenomenon formed by values and attitudes which influence social interactions among the members' group.

Fadama members'participation can be referred as a process of involving local people in to government policy like planning process, decision making and implementation (Soen, 1981). From this definition given by (Soen, 1981) we can elaborated that participation is the involvement of local people's inthe policies like decision making, planning and implementation through the use of a well-organized associations like Fadama User Groups (FUGs) which can serve as medium of social capital creation and empowerment in Kankara local community. In which their members are working together to bring changes from the grass root, through coordination, co-operation, and collaborative effort (3c's).

Meanwhile, participation inFadama User Groups (FUGs) requires human effort/inputs, skills and ability for members' maximum satisfaction and community development. And the above assertion was supported by (Rahim M. Sail \&Asnarulkhadi Abu-Samah, 2010) that participation is an active process. Similarly, objective two of the research work is to focus on: how participation in Fadama User Groups (FUGs) can serve as medium of social capital and empowerment in Kankara local community.Bretty (2003,p.5) has contributed his opinion toward this point; according to him he opined that participation is the process of empowering rural people. This participation process can be partnership with people, government and nongovernmental organizations through social capital. Furthermore, this can help members to boost in their sharing skills, experience and knowledge among the members group. Consequently it might lead them to have control over the available resources within the community. Participation and social capital can be referred as complimentary activities to empowerment. This can be achieved through (FUGs) members' involvement in the Fadama activities in Kankara local community. This participation can enhance the members' skills and abilities to plan, make decision and implement various project that can contribute to members empowerment and community development (France, 1998).

Lastly a lot of literatures disclosed that participation, social capital and empowerment are closely related. This assertion was supported by work of (Berger and Neuhaus, 1977; Rapapport, 1987; Schulz et'al 1995). Another work similar to the above related literature was also digested. The work of McCall and Minang (2005) shows that functions of communal efforts or people participation in the field of Geographic Information 
System (GIS), Resource Management (RM), Political and Environmental Resources Strategic Mapping (PERSM) are of more better off, if it involves community participation process. Another finding by Eade and Williams (1995, p.12) highlighted that "empowerment is a measure of peoples' capacity to brings about changes which is concerned with analyzing and addressing the dynamics of oppression and assisting groups and individuals to play an active role in the decisions and changes that affects the social system". Communities with higher level of citizen's participation were much more likely to have citizen control and social capital in their governing boards then those who lack such involvement (Reid, 2000, p.6).

\section{Problem Statement}

The researcher found it beneficial to conduct a research in the field of peoples' participation inFadama User Groups (FUGs) as a medium of social capital and empowerment in Kankara local community, Katsina state, Nigeria. The issues which attract the researcher to conduct research work on this topicisdue to low participation and social capital observed among the local community members. Meanwhile the problem of low empowerment was also observed among the local community members.

\section{Objective of the research}

Three main objectives were outline by the researcher to solve the above traceable problems observed in the local community.

$>$ To describe the level of participation, social capital and empowerment in Kankara local community.

$>$ To examine the strength of relationship among the (FUGs) members'in participation, social capital and empowerment.

> To explorehow participation in Fadama User Groups (FUGs) contribute to social capital and empowerment.

\section{Methodology}

The method employed by the researcher to work out this research objectives successfully were through the use of an instrument that was tested its reliability and validity in the field before the real application for the main data collection. This instrument used was the structured designed questionnaire which was administered to collect information from 285 population sample sizes, in Kankara local community. The selection of the respondents was done by using stratified random sampling techniques; in order to have equal representation from each village area and to avoid gender bias. The research also used descriptive statistics to find out the level of participation social capital and empowerment. And Pearson correlation analysis was run to find the strength of the relationship among the Fadama User Group (FUGs) in participation, social capital and empowerment in Kankara local community. Lastly regression analysis was also done to find out how participation in Fadama User Groups (FUGs) contributes to social capital and empowerment.

\section{Result finding and discussion}

Table 1: level (Empowerment, Participation and Social Capital)

\begin{tabular}{lcccc}
\hline Variables & $\mathbf{N}$ & $\mathbf{\%}$ & Mean & SD \\
\hline Participation & & & 42.96 & 2.89 \\
\hline Low(26-52) & - & - & & \\
Moderate(52.1-78) & 67 & 23.5 & & \\
High(78.1-104) & 218 & 76.5 & & \\
\hline Social Capital & & & 41.99 & \\
\hline Low(13-26) & 14 & 4.9 & & \\
Moderate(26.1-39) & 21 & 7.4 & & \\
High(39.1-52) & 250 & 87.7 & & \\
\hline Empowerment & & & 88.87 & \\
\hline Low(13-26) & 18 & 6.3 & & \\
\hline Hoderate(26.1-39) & 82 & 28.8 & & \\
\hline
\end{tabular}

Source: Field work, 2013.

Table 1:is to describe the level of participation, social capital and empowerment. Results shows that 218(76.5\%) was emerged as high level of participation among the respondent in Fadama User Group (FUGs) activities. While $67(23.5 \%)$ was emerged as the moderate level of the respondentparticipation in Fadama activitiesand no single member falls within the lower level of participation. This happens due to their active participation inFadama User Groups (FUGs) among the respondent. Moreover, the success achieved was due to the nature ofFadama members' participation in FUGs, Kankara local community, Katsina state, Nigeria. People prepared to become involve seriously because of their intention of getting the maximum level of empowerment (self-reliant and self-control). 
Similarly, results shows that $250(87.7 \%)$ was recorded as high level of social capital among the respondents. Meanwhile, the score of 21(7.4\%) was recorded as moderate level of social capital among the respondent. While, 14(4.9\%) emerged as low level of social capital among the respondents. From the results analysis it indicated that majority of the respondents were within the high level of social capital.While, results indicated that $185(64.9 \%)$ emerged as high level of empowerment. While, $82(28.8 \%)$ was to reflect the moderatelevel of empowerment.Meanwhile, 18(6.3\%) was recorded as low level of empowerment achievement among the respondents. The summary of this results shows that there was high level achievement of empowerment, social capital and participation among the respondents inFadama User Groups (FUGs) activities in Kankara local community, Katsina State-Nigeria.

The general overview of the results analysis shows that, there was high level of participation and rising achievement of social capital which consequently yield the resulted out comes to appear high in the empowerment level among the members of Fadama User Groups (FUGs) in Kankara local community Katsina State, Nigeria.

\section{Relationship between participation, social capital and empowerment through Fadama activities}

Pearson correlation analysis was also used to examine the strength of the relationship between participation,social capital and empowerment among the members' of FadamaUser Groups (FUGs) in Kankara local community.

Table 2; below shown that there is significant positive medium relationship between participation and social capital $(\mathrm{r}=.343, \mathrm{p}=.000)$. And thisfinding was supported by an empirical research conducted on people participation, trust and social capital on the civil space by Veenstra, G. (2002) the findings shows that the Length of time in the neighborhood (experience in the participation) was significantly related to both social capital achievement (tau_b $=0.230, \mathrm{p}<0.001)$ and political trust (tau_b $=0.115, \mathrm{p}<0.001)$. Another findings by Bretty (2003, p.5), shows that participation process partnership with peoples, government and non-governmental organizations can create social capital as a result of members' involvement. This can help in boasting the sharing skills, experience and knowledge among the members group. Consequently it might lead to members having control over the available resources in that community (empowerment). Because of the relationship they were able to build/created among the FUGs members. Table 2: below shows the relationship.

Table 2: RelationshipbetweenParticipation and Social Capital

\begin{tabular}{llc}
\hline \hline Variables & $Y$ & $\chi_{1}$ \\
\hline$Y$ (Participation) & 1 & \\
$\chi_{1}$ (Social Capital) & $.343^{* *}$ & 1 \\
\hline \hline
\end{tabular}

*Correlation is significant at 0.05 levels (2-tailed).

Meanwhile,the data collected was also use to find the strength of relationship between social capital and empowerment through Fadama activities. The Pearson correlation analysis was done and the result findings reflect that, there is significant positive medium relationship between social capitaland empowerment $(r=.396$, $\mathrm{p}=.000$ ). This result was supported by finding from many scholars; among them include the work of: Burt $(1992,1997)$ whose findings shows that individual members are able to use their network position to fill some of the structural holes that exist or boundary spanner within inter and intra community based organization. In fact, centrality in the advice network has been linked to empowerment (Sparrowe, Liden, Wayne, \&Kraimer, 1997).Another finding by Granovetter (1973) shown that weak ties are more likely efficient for FadamaUser Groups (FUGs) members to achieve high level of empowerment then the strong ties in social capital. Because weak tie can create a gap among the Fadama User Groups (FUGs) and this can provide a mentor/ego the opportunity to connect them. As a result of that they may benefit each other in Fadama activities toward the centrality of outcomes (empowerment). The strength of the relationship was shown in table 3 below:

Table 3: RelationshipbetweenEmpowerment and Social Capital

\begin{tabular}{llc}
\hline \hline Variables & $\mathbf{Y}$ & $\chi_{1}$ \\
\hline$Y($ Empowerment) & 1 & \\
$\chi_{1}$ (Social Capital) & $.396^{* *}$ & 1 \\
\hline \hline
\end{tabular}

*Correlation is significant at the 0.05 level (2-tailed).

Moreover, the research went ahead to find out the strength of the relationship between participation and empowerment. In this analysis also the Pearson correlation analysis was conducted to examine the relationship between participation and empowerment. As illustrated in Table 4: below, result shows that there is significant positive medium relationship between participationand empowerment among the respondent $(r=.346, p=.000)$. This finding was supported by the work of: Lim, Ying Ying (2010) her finding shows that there was relationship between participation and empowerment and the results indicated that $(r=0.599$ and $p<.0001)$. And the 
relationship is highly significant at $(\alpha=1 \%)$ which means that the higher the level of participation (likely in the planning, implementation and evaluation process), the higher the level of empowerment (like awareness, human capital and experience). This result finding was also supported by work of Ahmad ShukriAbdul Hamid (2008) whichshows that people participation can contribute to their empowerment.Another scholarly findings was also supported the result, example the work of:Eade and Williams (1995) discovered that "empowerment is a measurement of peoples' capacity to brings changes on which more or less concerned with analyzing and addressing the dynamics of oppression and assisting groups and individuals to play an active role in decision making and changes that may affects their social system". People's with higher level of citizen's participation were much more likely to have citizen control and self-reliant (empowerment) in their governing boards and control over the available resources within the community, then those who lack such involvement (Reid, 2000, p.6). Table 4: was clearly illustrating that:

Table 4: RelationshipbetweenParticipation and Empowerment

\begin{tabular}{lll}
\hline \hline Variables & $\mathbf{Y}$ & $\chi_{1}$ \\
\hline$Y$ (Empowerment) & 1 & \\
$\chi_{1}$ (Participation) & $.346^{* *}$ & 1 \\
\hline \hline
\end{tabular}

**Correlation is significant at the 0.01 level (1-tailed).

*Correlation is significant at the 0.05 level (2-tailed).

Furthermore,the work ofLondon $\& \operatorname{Stumpf}(1982)$, also supported the finding in which they discovered that participation and social capital can work harmoniously to empowerment. Participation and social capital are seriously related (Aryee, Chay, \& Tan, 1994; Hall, 1976, Wayne, et al. 1999).And it can be refers as an individual members to be aware of the problems and to set-up required objectives and feelings of accomplishment and satisfaction to achievein the set goals, in the project activities of FadamaUser Groups (FUGs)toward the creation of people's participation. And this central objectives or target can be achieved by building sound network relationship and social cohesion among the member groups in order to achieve maximum empowerment level. Moreover, another finding conducted by:Eklund (1999), opined that the psychological sense of control, self-competence perceived by a member through human capital, experience, awareness and self-esteem as well as socio-political activities of the people's participation in Fadama User Groups (FUGs) can serve as medium to social capital creation and empowerment.

The below table 5: shows the correlation matrix of the above analysis; the strength of relationship between peoples' participation in Fadama User Groups $\left(\mathrm{X}_{1}\right)$ and social capital creation $\left(\mathrm{X}_{2}\right)$ as well as empowerment $\left(\mathrm{X}_{3}\right)$. The results analysis indicated that there is relationship between the three variables (empowerment, social capital and participation) at a significant value of $\mathrm{P}=0.000$. Correlation is significant at the 0.01 level (2-tailed) shown by Pearson correlation analysis table below.

Table 5: Correlation matrix

\begin{tabular}{|c|c|c|}
\hline $\mathrm{x}_{3}$ & $\begin{array}{c}\mathrm{X}_{3} \mathrm{X}_{2} \\
1\end{array}$ & $\mathrm{X}_{1}$ \\
\hline $\mathrm{X}_{2}$ & $.396 * * 1$ & \\
\hline $\mathrm{x}_{1}$ & $.346^{* *} .343^{* *}$ & 1 \\
\hline
\end{tabular}

**.correlation is significant at the 0.01 level (2-tailed).

To determine the unique predictors of people's Participation, Social Capital and Empowerment The factors contributing toempowermentare participation and social capital.Therefore, the model consists of two predicting variables namely; participation $\left(\chi_{1}\right)$ and social capital $\left(\chi_{2}\right)$. Therefore, the prediction equation is as follows:

$\hat{Y}=b_{o}+b_{1} \chi_{1}+b_{2} \chi_{2}+e_{1}$

Where:

$\hat{\mathrm{Y}}=$ empowerment;

$\chi_{1}=$ Participation; 
$\chi_{2}=$ social capital;

$\varepsilon=$ Random error.

The proposed hypotheses test which examines the validity of the model is expressed as follows:

Ho: $\mathrm{Y}=\beta_{0}+\mathrm{e}_{\mathrm{i}}$

$\mathrm{H}_{\mathrm{A}:} \mathrm{Y}=\mathrm{b}_{\mathrm{o}}+\mathrm{b}_{1} \chi_{1}+\mathrm{b}_{2} \chi_{2}+\mathrm{e}_{\mathrm{i}}$

The multiple regression analysis shows that; the totalparticipation in Fadama User Groups creation has the higher beta co-efficient which contributed to high empowerment level, due to the fact that $(\beta=.238, \mathrm{t}=4.208$, $\mathrm{p}=.000)$ and the result of the social capital beta shows that the co-efficient of $(\beta=.315, \mathrm{t}=5.577, \mathrm{p}=.000)$. The results finally show that there are mutual transgressed factors from participation and social capital to empowerment, considering $\left(\mathrm{R}^{2}=.207\right.$, adjusted $\left.\mathrm{R}^{2}=.201\right)$.

The regression analysis has also indicated that, the two variables were regressed to empowerment. As $\left(\chi_{1}\right)$ refers to participation; and $\left(\chi_{2}\right)$ refers to social capital, then $\left(\chi_{3}\right)$ equals to empowerment. For example:

$\hat{Y}=b_{o}+b_{1} \chi_{1}+b_{2} \chi_{2}+b_{3} \chi_{3} e_{i}$

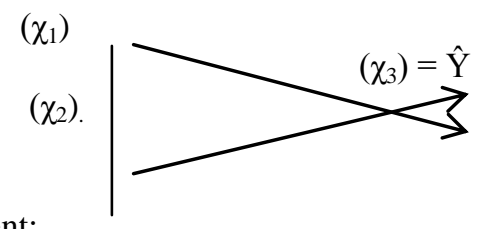

$\hat{Y}=$ empowerment;

$\chi_{1}=$ Participation;

$\chi_{2}=$ social capital;

$\chi_{3}=$ transgressed to empowerment

$\varepsilon=$ Random error.

The above diagram description shown; how the both participation and social capital creation were regressed to empowerment. Moreover, the Mathematical derivative of the regression equation for the empowerment model is as follows:

$\hat{Y}=21.047+(.111) \chi_{1}+(.136) \chi_{2}+$ Error

Participation in Fadama User Group(FUGs) can serve as a medium of social capital and empowerment considering $\left(\mathrm{R}^{2}=.207\right.$, adjusted $\left.\mathrm{R}^{2}=.201\right)$.

\section{Result Discussion}

Result from this empirical research shows thatthe level at which participation in Fadama User Groups serve as a medium to social capital and empowerment was high, because the analysis indicated that the level of participation is high at $218(76.5 \%$ ) out of 285 total respondent and (mean=42.96, $\mathrm{SD}=2.89$ ). While the social capital level is also high from the result to $250(87.7 \%$ ) out of 285 respondent and (mean=41.99, SD=5.86). Similarly, result from empowerment shown high with 185(64.9\%) out of 285 respondent and (mean=88.87, $\mathrm{SD}=7.76$ ). this result prove that participation in Fadama User Groups (FUGs) can serve as medium to social capital and empowerment. In addition to that, the strength of relation examined also prove the issue under discussion, because the results indicated thatthere is significant positive medium relationship between participation and social capital with $(\mathrm{r}=.343, \mathrm{p}=.000)$. Meanwhile, the relationship between social capital and empowerment is significant at $(\mathrm{r}=.396, \mathrm{p}=.000)$ by using the Pearson correlation analysis. And the relationship strength between participation and empowerment was also analysed and result shows that there is significant medium relationship between themat $(\mathrm{r}=.346, \mathrm{p}=.000)$. These results proved that participation in Fadama User Groups can also serve as a medium to social capital and empowerment in Kankara local community, Katsina state, Nigeria. This finding was also supported by Ahmed Shukri Abdul Hamid (2008), where he opined that in order to achieve empowerment; it requires active participation from the community members'. The regression analysis also prove that Participation in Fadama User Group (FUGs) can serve as a medium of social capital and empowerment considering $\left(\mathrm{R}^{2}=.207\right.$, adjusted $\left.\mathrm{R}^{2}=.201\right)$. 


\section{Summary and Conclusion}

Conclusively, the research has come to it success in which all the designed objectives were achieved successfully. The level at which participation in Fadama User Groups (FUGs) serve as medium to social capital and empowerment was analyzed through descriptive statistics and the results shows high in all the three variables.Secondly the strength of the relationship was also examined through Pearson correlation analysis and result confirmed that there is significant medium relationship between all the three variables. Finally the correlation analysis was used tofind how participation in Fadama User Groups can contribute to social capital and empowerment. Theregression analysis was conducted and it proved that participation in (FUGs) can contribute significantly tosocial capital and empowerment in Kankara local community, Katsina state, Nigeria.And practical the issue of participation in Fadama User Groups (FUGs) activities in Kankara local community and Katsina state in general its create sense of belonging among the members and built trust, understanding as well as mutual relationship (social capital). Similarly Fadama activities can make use of ideas, knowledge, resourcefulness, human capital, experience and awareness among the participating members.

\section{Recommendation}

The researcher is boldly recommending that; the only modern weapon remain for the rural poor to attack the present challenge on poverty hiking in the world over is by the use of peoples' participation and social capital for community empowerment and sustainable development. Moreover, the researcher is recommending that our teaming youth has to be part of this initiative. Finally, the research wanted to use this avenue and call the attention of government and non-governmental organization to improve the support given to those associations for community and sustainable development.

\section{References}

[1] Ahmad Shukri Abdul Hamid (2008) Empowering the Marginalized: the role of social capital andCivil society. In FuziahShaffie and RozitaYusoff.(eds) (2008). University Utara Malaysia.

[2] Alison, H. (2010) "Public Participation Theory and Practice," LCA, CPD Training Program. Heritage council; www.heritage.council.ie

[3] Aryee, S., Chay, Y.W., \& Tan, H.H. (1994)An examination of the antecedents of subjective career success among a managerial sample in Singapore. Human Relations, 47: 487-509.

[4] Berger, P.L. and Neuhaus, R.J. (1977) To Empower People: The role of mediating structure in public policy. Washington DC: American enterprise institute for public policy research.

[5] Bourdieu, P. (1983) 'The Forms of Capital.' Pp. 241-58 in Handbook of theory and research For sociology of education, edited by John G Richardson. New York: GreenwoodPress.

[6] Bullen, Paul, and Jenny Onyx.( 2000) 'Measuring Social Capital in Five Communities in NSW.'Pp. 49: Centre for Australian Community Organisations and Management (CACOM) CACOM Working Paper Series (No 41).

[7] Burt, R. S. (1992) Structural holes: The social structure of competition. Cambridge, MA: HarvardUniversity Press

[8] Burt, R. S. (1997) The contingent value of social capital. Administrative Science Quarterly, 42:339-365.

[9] Bretty, E.A. (2003) Participation and Accountability in Development Management. The Journal of Development Studies, 40(2), pp. $1-29$

[10] Cohen, J.C. \&Uphoff, N.T. (1977) Rural Participation: Concept and Measures for project design, Implementation and evaluation. Monograph No. 2, New York: RuralDevelopment Committee, Centre of International studies, Cornell University.

[11] Cross R. and Cumming, J.N. (2004) "Tie and Network Correlates of Individual Performance In Knowledge-Intensive Work", Academy of Management Journal. 7, 6 928-937.

[12] Eadeand Williams, (1995) The Oxfam Handbook of Development and Relief. Oxford: Oxfam UK and Ireland.

[13] Eklund, L. (1999) From Citizen Participation Towards Community Empowerment: An Analysis on Health Promotion from Citizen Perspectives: Tampere: University Of Tampere.

[14] France, L. (1998) Local Participation in Tourism in the west Indian Islands. In Laws, E., FaulknerB. and Moscardo, G. (eds) Embracing and Managing Change in Tourism: London, Routledge.

[15] Gittel, R. and Thompson, J.P. (2001) Making Social Capital work: Social Capital and Community Economic Development. In Saegert, S, Thompson, J.P. and Warren, M.R.(eds). Social Capital and poor Communities.New York Russell Sage Foundation, pp. $115-135$.

[16] Granovetter, M.S.(1973) "The Strength of Weak Ties," American Journal of Sociology (78:6), May 1973, pp 1360-1380.

[17] Hall, D.T. (1976) Careers in organizations. Santa Monica, CA: Goodyear.

[18] Krejcie and Morgan, (1970) "determining the size of population sample by using random sample table. Research Method in Education ( $5^{\text {th }}$ edition); published in USA andCanada by Routledge falmer (2002) revised edition.

[19] Laverack, G. (2006) Improving Health Outcomes through Community Empowerment. AReviewof the literature. Journal of Health, Population and Nutrition, 24(1): 113-120

[20] Lim, Y.Y. (2009) "Empowering the semai people through participation in community development program" Msc. Thesis Submitted to faculty of Human Ecology, University Putra Malaysia.

[21] London, M., \&Stumpf, S. A. (1982) Managing careers. Reading, MA: Addison-Wesley.

[22] McCall, M. and Minang, P.A. (2005) Assessing participatory GIS for Community based Natural Resources Management. The Geographical journal, Vol.171, No.4: 340-356.

[23] Newton, K. (1997) Capital and Social Capital, in turn helps in Strengthen Political Institutions,HavardUniversity Press.http://www.hks.harvard.edu/fs/pnorris/Acrobat/pdf

[24] Osirim, M.J. (2001) Making Good on Commitments to Grassroots Women: NGOs and Empowerment for Women in Contemporary Zimbabwe. Women Studies International Forum, Vol.24(2): 167-180.

[25] Putnam, R.D. (2000) Bowling Alone. The Collapse and Revival of American Community. Network: Simon and Schuster. 
[26] Plateau, W. W. and Moore, M. M. (1994) Southwestern Ponderosa Forest Structure and Resource Conditions: changes since EuroAmerican settlement. Journal of Forestry 92: 39-47.

[27] Rahim, M.S. and Asnarulkhadi, A.S. (2010) Community Development through Community Capacity Building: A Social Science Perspective. Journal of American Science 2010; 6(2): 68-76. Marsland Press.

[28] Rappoport, J. (1987) Terms of Empowerment /Exemplars of Prevention: Toward a Theory ForCommunity Psychology.American Journals of Community Psychology, 15(2), 121-143.

[29] Reid, J.N. (2000) Community Participation: How people power Brings Sustainable Benefits To Community.http://www.rurdev.usda.gov/rbs/ezec/pubs/commparticrept.pdf USDA Rural Development: Office of Community Development (Pg.1-13).

[30] Soen, (1981) "Social problems and Crime in the metropolitan Area of Tel-Aviv" paper Presentedat International Conference on social defense, Athens, Greece at Tel-Aviv.

[32] Schulz, A.J; Israel, B.A; Zimmerman, M.A. \&Checkoway, B.N. (1995) Empowerment as a multi-level Construct: Perceived Control at the Individual, Organizational and Community Levels Health Education Research: Theory \& Practice, 10(3), 309-327

[33] Sparrowe, R. T., Liden, R. C., Wayne, S. J., \&Kraimer, M. L. (1997) Exchange Processes, Social Structure and Performance. Paper presented at the SouthernManagement AssociationMeetings, Atlanta, Georgia.

[34] Veenstra, G. (2002) "explicating Social Capital: Trust and Participation in the Civil Space” Canadian Journal of Sociology 27(4): 547-572.

[35] Wayne, S. J., Liden, R. C., Kraimer, M. L., \& Graf, I. K. (1999) The role of human capital, motivation, and supervisor sponsorship to career success. Journal of Organizational Behavior, 20: 577-595.

[36] White, L. (2002) "Connection matters: exploring the implications of social capital and social netowrks for social polcy." Systems Research and Behavioral Science 19: 255-269. 